\title{
Comparison of Value Added within EU in Terms of Corporate Investment in Research and Development
}

\author{
Yaroslava Kostiuk $^{1, *}$, Kristína Korená ${ }^{1}$ \\ ${ }^{1}$ Institute of Technology and Business, Faculty of Corporate Strategy, Okruzni 517/10, 37001 Ceske Budejovice, Czech Republic
}

\begin{abstract}
Globalization has accelerated the growth of innovation in many countries outside the European Union. In order to remain competitive, companies and individual EU economies therefore support the development of innovations through investments in research and development.

This contribution is focused on the specification of value added in terms of investments in research and development in the construction and manufacturing sectors. Using statistics of the European Commission for the period 2013 - 2017, a dataset of 269,892 companies in the EU28 countries was generated.

The purpose of this contribution is to determine to what extent investment in research and development participates in the creation of value added. A research question was formulated to determine the ideal ratio between value added and investment.

Methods: To achieve the objectives set, regression analysis of neural networks was applied using Statistica software.

The results of the research indicate that the optimal values in the construction sector were achieved by Great Britain ( EUR 11.3 billion.) and France ( EUR 16.1 billion), and in the manufacturing sector by France ( $\sim$ EUR 11.42 billion), Italy ( $\sim$ EUR 11.41 billion) and Great Britain ( $\sim$ EUR 10.6 billion).

The authors consider the method of regression analysis and neural networks to be appropriate for examining the optimal ratio between investment in R\&D and value added.

Keywords: value added; investment; research and development
\end{abstract}

\section{Introduction}

Investment in research and innovations has been an important part of the EU's coordinated response to the pandemic outbreak in 2019/2020, which is necessary for sustaining an inclusive recovery within Europe. These incentives for research and development are relevant because they increase the resistance of the manufacturing sector, competitiveness of economies, prepare individual countries for the future, and play a key role in achieving the goals of the European Union [1]. This contribution deals with the influence of corporate investment in research and development on the value added of the EU countries.

For the EU countries, innovations are an important component of sustainable international competitiveness. It is for this reason that the European Commission creates a multi-annual budget and prepares an investment plan to determine which direction all the member states will go in in terms of investment in research and development. According to the data obtained from [2], in the period 2008-2017, EU member states fell behind other developed economies, such as the USA, Japan and South Korea in the area of research and development.

Foreign-owned companies invest twice as much as Czech-owned companies in research and development and other investments. Czech industry lacks innovation, the development of new technologies, and a focus on research, which limits the development of production with value added [3].

It is therefore necessary to find out what opportunities are lost or how much value-added economies may lose if they do not use innovations in industry and do not use all the subsidies intended for development. It is also necessary to determine the optimal value of investments for the EU28 economies in order to be competitive in the global value chain.

If investment in research and development is so important for creating corporate value added, why is the level of investment not determined by the real needs of companies and the investments possibilities of individual countries? How has investment in research and development evolved since the establishment of the EU and how has the COVID-19 pandemic affected the given field?

The objective of the contribution is to find out to what extent investment in research and development participated in the creation of value added for the EU28 countries in the period 2013-2017. We assume that a strong connection between

\footnotetext{
* Corresponding author: 26567@mail.vstecb.cz
} 
the given items will be confirmed. As a result, special attention will be focused on those industries that create the highest value added - manufacturing and construction. The following research question was formulated:

What is the ideal ratio between value added and investment?

By answering the question, it will be possible to find out which member states invest inefficiently and therefore have room for better and more effective use of investment, as well as for achieving overall value added.

One of the most significant effects of globalization has been the increase in global value chains (GVC) [4]. Their modernization is explicitly connected with the long-term growth of companies and product innovations [5]. Globalization has accelerated the increase in innovation in many countries outside the European Union (EU). To therefore remain competitive, companies or individual EU economies support the development of innovations by investing in research and development (R\&D).

The most popular definition of investment in scientific literature was created by [6], who defines investment as a current sacrifice for future prosperity, and defines the present as a relatively well-known variable, whereas the future is a mystery. That is why in this case, investment is seen as a certain sacrifice for uncertain profit. [7] defines innovation as new ideas which are in reality applied in various ways to generate new or additional value.

[8] proposed a complex investment framework - the Innovation Value Chain (IVC). In their work, the innovation value chain is seen as a gradual three-phase process: gathering knowledge, transformation of knowledge, and its application [9].

[10] point out that the purpose of innovation is much broader than the simple creation of value for a customer, competitive advantage for companies, and environment for a better quality of life. In accordance with the authors' view, the objective of innovation should be the creation of a better, intelligent future.

The issue of the influence of investment in R\&D was addressed by [11], who examined the effectiveness of research and development using the Malmquist index. The index indicated that 15 out of $28 \mathrm{EU}$ countries evaluated showed an increase in the effectiveness of research and development between 2010 and 2015, with Italy and Germany showing the highest increase.

[12] analysed the relationship between investment in research and development and economic growth in 25 EU countries. Multiple regression analysis was used to confirm the strong impact of investment at the regional level for distances of more than $200 \mathrm{~km}$. In their research, they highlight the importance of vicinity for the transfer of economically productive knowledge.

[9] focused on a comparative panel-data analysis of the innovation value chain in Irish and Swiss production companies. Panel-data analysis was used to examine the influence of innovations on productivity. They concluded that in both countries, the measures adopted to support the development of skills will have a positive impact on the innovation and productivity in both countries. However, there were differences in the case of the relationship between innovation and productivity, as in Ireland, process innovation is more important, while in Switzerland, product innovation is.

[13] investigated how the level of participation in global value chains (GVC) affects corporate innovation activities in Japanese companies. On the basis of the results, he emphasized the importance of GVC in supporting the innovative abilities of a company, which enables companies and countries to upgrade within the value chain.

[14] studied the relationship between the participation in (GVC) and innovative performance at country level. Their findings proved that participation in GVC positively correlates with the level of innovation within a country.

[15] investigated how the combination of approaches related to GVC and innovation systems may enable us to understand the trajectories of education and innovation in developing countries. They found that in some cases, there is an improvement in local innovative capacity with potential positive effects on overall competitiveness, while in other cases, there is only a small improvement or even loss of innovative capacity.

[16] examined the role of intellectual capital in the participation and re-valuation of value in GVC on a sample of European countries. They found that intangible assets other than R\&D play a more important role than research and development, while the main driver of the participation is training. The evidence presented in the article also shows that some countries may be trapped in a vicious circle of low investment in activities that create high value added and low competitiveness in international markets.

[17] examined the relationship between innovation and the participation of companies in GVC on a sample of 90 countries. Their empirical estimation was made using a probit model which enabled them to estimate the participation probability of innovative enterprises in value chains. Empirical analysis revealed a positive and significant influence of innovation on companies' participation in GVC.

[18] used the matching method to test whether the public funding makes Spanish industrial companies invest in research and development. The research results did not show any effect of public funding on investing in R\&D. Public 
funding is more efficient in the case of small companies and in companies operating in industries with a low level of technology. In their observations, González and Pazó also point to the delayed result in estimating the effect of R\&D funding.

EU member countries, which are among the world's economically most developed economies, should make significant profit from investment in research and development [19]. Since the EU is aware of the importance of these investments in the long term, a strategic plan was accepted in Barcelona in 2002, according to which the investment in innovations within R\&D should achieve 3\% of GDP per year until the year 2010, whereby two thirds of the investment should come from the private sector [20]. Unfortunately, the achievement of the $3 \%$ investment target is not feasible for all member countries because "investment in research and development in the EU declines from the north-west to the south-east" [21, p. 3]. According to Eurostat [22], at the time of the adoption of this strategic plan, the required level of investment was achieved only in Finland and Sweden. Other EU member states showed much lower levels of investment in R\&D, e.g. in the Czech Republic, it was $1.1 \%$ of GDP. The goal to get close to the required value by 2010 was very ambitious and other EU countries did not manage to achieve it after overcoming the crisis of 2008. According to the latest data, for 2018, other member countries have since achieved the goal, e.g. Denmark, Germany, Austria, Slovenia. Investment in $R \& D$ is a driver of innovation. As innovation is synonymous with change, EU economies need significant changes in their budget policies to gradually strengthen their own value added by means of innovation.

To compare global investment processes among the members of the United Nations (UN), investment in R\&D within the overall context of innovative development is monitored by means of Global Innovation Index (GII). In 2017, a total of 126 countries were evaluated within GII. The highest GII value was achieved by Switzerland, followed by the Netherlands, Sweden, Great Britain, Singapore, the USA, and Finland. The Czech Republic occupied the $24^{\text {th }}$ position, while in 2018, it dropped to $27^{\text {th }}$ position [23].

Every two years since 2002, the Czech Statistical Office has been conducting statistical surveys on the innovative activities of companies (see Figure 1). Innovative companies in the Czech Republic are mostly foreign controlled companies, which are mostly large companies operating in industry. At the same time, the share of foreign controlled companies is high, especially in terms of medium-sized and large companies $(50-75 \%)$.

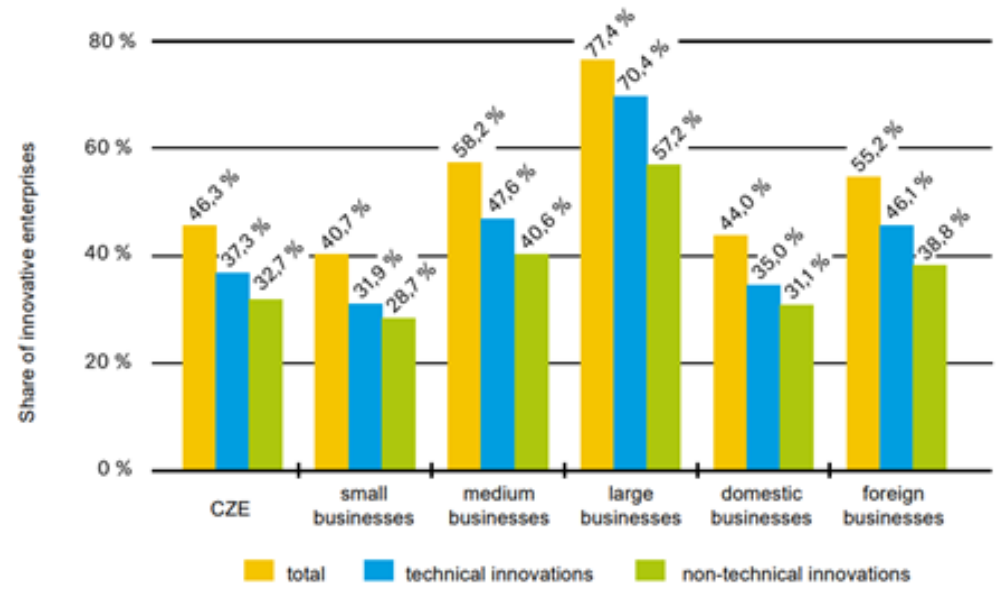

Figure 1. Share of innovative Czech companies by type of innovation (2014-2016)

Source: [23].

This indicates their importance for the innovative performance of the Czech Republic and the necessity for cooperation between the public sector and this segment of R\&D [23].

For research and development to be a driver of economic growth in the EU, investment in this field should be properly distributed in order to transform the European economy as a whole [24]. People often point to the delay between economic activities and their consequences, referred to as time lag, which starts with the investment in research and development and ends with the actual economic return on investment [25]. From the macroeconomic perspective, EU funds are considered as an attractive instrument for funding investment opportunities, especially in times of crisis, when private investment declines [26]. The global crisis caused by the COVID-19 pandemic is growing at an exponential rate, and the associated growing uncertainty is leading to the loss of investment and escalating fluctuations in international trade [27]. In our opinion, the COVID-19 pandemic has undermined the overall economic ambitions of the world economies, and as research and development needed financial investment even before the pandemic outbreak, it will be even more difficult to achieve the goals set after the pandemic ends. The growth of investment can be assumed in sectors such as health, logistics and digital technologies, which will subsequently be reflected in their increased value added. However, sectors such as manufacturing, construction and logistics have become less attractive during the pandemic. This is evidenced by reduced production in large manufacturing companies, the cancellation of many flights due to the reduction of travel 
opportunities, etc. As [24] state, the achievement of national goals is not only a question of financial possibilities, but also of mutually beneficial research alliances between the public and private sectors. In the history of European investment in $\mathrm{R} \& \mathrm{D}$, it has become commonplace that the EU budget includes funds for innovation; however, the number of patents is not enough to obtain support from the state. This problem is also associated with the lack of experts and researchers who might put forward and adapt innovations to the actual needs of states and according to EU priorities. [19] argue that realistic national goals may stimulate patent activities provided that there is a suitable environment and cooperation between public and private research activities. According to the authors, investment in research and development is of the highest priority in countries that lie in the north-west of the block (Scandinavia), whilst the priority is declining in those countries that lie in the south-west of the block (Mediterranean and Balkans). Growth potential is unevenly distributed among the EU member states; as a global player, the EU must ensure that the potential growth in R\&D supports the economic recovery of the EU as a whole [24].

The theoretical framework shows that the issue of investment in research and development has a positive impact on the development of the value added chain. Moreover, studies have repeatedly confirmed the relationship between investment in R\&D and economic growth, both at the level of states and regions, as well as companies.

The aforementioned studies included more than two factors that would affect the relationship between innovation and global value chains, which naturally enabled a more detailed description of this relationship. At the same time, however, the studies were not focused on determining the optimal value of R\&D investment for individual industrial sectors. In our research, regression analysis is used to focus on two data time series, the use of which will make it possible to determine the optimal level of investment required to achieve the desired indicator of value added.

\section{Methodology}

The aim of this contribution is to analyse the investment of individual countries and the generated value added. The answer to the research question is the ideal ratio between investment and value added. To avoid and eliminate extreme values it is appropriate to use a regression model. As stated above, information on country-specific investment and the generated value added will be used for the analysis. For the purposes of this contribution, data based on published statistics of the European Commission for the period 2013-2017 were used:

1) Data on investment in research and development in the EU28 countries in the manufacturing, construction and sectors were used from published Eurostat data [1].

2) Data on the value added of individual countries were drawn from the Eurostat-OECD Entrepreneurship Indicator Programme [1].

The generated dataset included a total of 269,892 companies from across the European Union, of which 74,759 companies from the construction sector and 195,133 companies from the manufacturing sector.

For all the calculations, TIBCO's Statistica software (version 13.0) was used. For the analysis, artificial neural networks are used to examine the dependence of investment and value added in the construction and manufacturing sectors of individual EU countries in the period 2013-2017. At the same time, the relationship will be examined through the application of neural networks. Neural networks provide efficient image recognition, prediction, optimization and control of processes, and adaptation of linear and nonlinear functions [28].

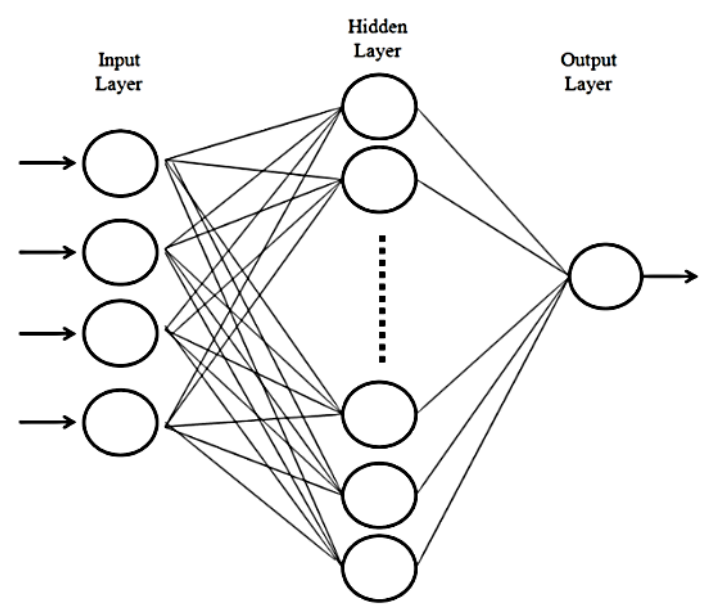

Figure 2. Neural networks

Source: [29]. 
Specifically, these will be multilayer perceptron networks (hereinafter MLP) and neural networks of radial basis function (hereinafter RBF). The data will be entered from the aforementioned sources, i.e. Eurostat. The Data mining tool neural networks will be used in the Statistica software, specifically, a section called Regression. First, the data is selected. The investments of a specific state are the independent variables. We understand the value added to be an dependent variable. Subsequently, the data is divided into three sets: training, testing and validation. The ratio is 70:15:15. Table 1 provides information on the basic statistics of the input data.

Table 1. Basic statistics of input data

\begin{tabular}{|l|c|r|r|r|}
\hline Statistics & $\begin{array}{c}\text { VA Total } \\
\text { construction }\end{array}$ & $\begin{array}{c}\text { Investment } \\
\text { construction }\end{array}$ & $\begin{array}{c}\text { VA Total } \\
\text { manufacturing }\end{array}$ & $\begin{array}{c}\text { Investment } \\
\text { manufacturing }\end{array}$ \\
\hline Minimum (Train) & 616.8 & 10.55 & 707.0 & 4.54 \\
\hline Maximum (Train) & 111850.8 & 53359.10 & 592027.2 & 58493.50 \\
\hline Mean (Train) & 19048.2 & 4701.88 & 70990.9 & 4327.45 \\
\hline Standard deviation (Train) & 28397.7 & 10861.67 & 110342.4 & 10008.83 \\
\hline Minimum (Test) & 497.7 & 7.26 & 1883.1 & 23.55 \\
\hline Maximum (Test) & 124704.8 & 58493.50 & 519792.5 & 49482.40 \\
\hline Mean (Test) & 33307.8 & 6977.28 & 58409.4 & 4308.50 \\
\hline Standard deviation (Test) & 41822.9 & 14455.32 & 122510.5 & 11770.55 \\
\hline Minimum (Validation) & 850.6 & 16.50 & 4541.6 & 23.05 \\
\hline Maximum (Validation) & 109303.8 & 10453.63 & 569863.5 & 53359.10 \\
\hline Mean (Validation) & 19466.6 & 2271.15 & 97360.2 & 5983.40 \\
\hline Standard deviation (Validation) & 27147.8 & 11656.49 & 125406.3 & 11247.96 \\
\hline Minimum (Overall) & 497.7 & 7.26 & 707.0 & 4.54 \\
\hline Maximum (Overall) & 124704.8 & 58493.50 & 592027.2 & 58493.50 \\
\hline Mean (Overall) & 21199.3 & 4679.12 & 72960.6 & 4561.31 \\
\hline Standard deviation (Overall) & 30397.8 & 10719.18 & 116861.0 & 10607.58 \\
\hline
\end{tabular}

Source: Authors.

The input data concerns data on the amount of investment in research and development and value added in the construction and manufacturing sectors for the period 2013-2017. Subsequently, on the basis of the training dataset, suitable neural networks are identified that best describe the relationship between the independent and dependent variables. On the basis of the testing and validation datasets, it is then verified whether the identified neural structures are adequate and faithfully describe the situation.

10,000 neural structures are generated, of which the top 5 in terms of performance and error are retained. For MLP, a minimum of 2 and a maximum of 20 neurons in the hidden layer applies. To activate the inner and outer layers of neurons, the following functions are used:

- Identity;

- Logistics;

- Hyperbolic tangent;

- Exponential;

- $\quad$ Sine.

In the case of RBF, a minimum of 11 and a maximum of 30 neurons in the hidden layer applies.

\section{Results and Discussion}

Based on the procedure above, the following statistical calculations were made for the construction and manufacturing sectors

Construction sector. Table 2 provides an overview of the five most successful neural networks that were retained.

Table 2. The five most successful neural networks for the construction sector

\begin{tabular}{|c|c|c|c|c|c|c|c|c|c|c|c|}
\hline 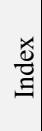 & 辛号 & 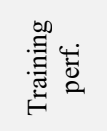 & 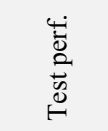 & 营 & 兽苛 & $\begin{array}{l}\overrightarrow{0} \\
\stackrel{0}{0} \\
\overrightarrow{0} \\
\stackrel{0}{0}\end{array}$ & 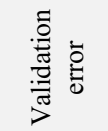 & 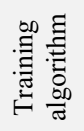 & 虽泀 & 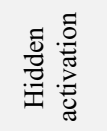 & 言. 逽 \\
\hline 1 & RBF 1-16-1 & 741394 & 0.698510 & 0.886277 & 28507279 & 50464189 & 18596061 & RBFT & SOS & Gaussian & Identity \\
\hline 2 & RBF 1-18-1 & 0.853169 & 0.436614 & 0.895073 & 15854994 & 121745126 & 1167300 & RBFT & SOS & Gaussian & Identity \\
\hline 3 & RBF $1-18-1$ & 0.805408 & 0.739256 & 0.902445 & 20644240 & 45729420 & 6074010 & RBFT & SOS & Gaussian & Identity \\
\hline 4 & RBF 1-21-1 & 0.804324 & 0.599527 & 0.893076 & 20956051 & 67124939 & 4037686 & RBFT & SOS & Gaussian & Identity \\
\hline 5 & RBF 1-20-1 & 0.721194 & 0.628954 & 0.898485 & 27961883 & 63696129 & 1210406 & RBFT & sos & Gaussian & Identity \\
\hline
\end{tabular}

Source: Authors. 
The identified neural networks were selected by the programme from 1000 neural structures on the basis of performance. For these networks, the basic prediction statistics were subsequently calculated, as presented in Table 3.

Table 3. Basic prediction statistics for investment (construction sector)

\begin{tabular}{|l|r|r|r|r|c|}
\hline \multirow{2}{*}{ Statistics } & \multicolumn{5}{|c|}{ Predictions statistics. Target: Investment } \\
\cline { 2 - 6 } & 1. RBF 1-16-1 & 2. RBF 1-18-1 & 3. RBF 1-18-1 & \multicolumn{1}{c|}{4. RBF 1-21-1 } & 5. RBF 1-20-1 \\
\hline Minimum prediction (Train) & -6462.8 & -441.5 & -159.9 & -3475.1 & -5514.1 \\
\hline Maximum prediction (Train) & 34384.4 & 53756.8 & 32210.5 & 36954.3 & 45465.3 \\
\hline Minimum prediction (Test) & -6442.0 & -247.9 & -34.1 & -355.5 & -2311.1 \\
\hline Maximum prediction (Test) & 29085.4 & 52616.3 & 28394.6 & 35761.2 & 14437.2 \\
\hline Minimum prediction (Validation) & -4767.2 & -231.3 & -56.3 & -736.7 & -1602.9 \\
\hline Maximum prediction (Validation) & 23667.4 & 14158.2 & 22428.0 & 20886.3 & 14437.2 \\
\hline Minimum residual (Train) & -24575.8 & -16872.4 & -23547.6 & -28330.4 & -18554.6 \\
\hline Maximum residual (Train) & 23624.4 & 33657.5 & 27201.1 & 23280.9 & 37952.0 \\
\hline Minimum residual (Test) & -13494.8 & -36407.2 & -12804.0 & -20170.6 & -11136.4 \\
\hline Maximum residual (Test) & 34855.7 & 44342.2 & 36076.9 & 37634.2 & 44056.3 \\
\hline Minimum residual (Validation) & -13213.8 & -3704.6 & -11974.3 & -10432.7 & -3983.6 \\
\hline Maximum residual (Validation) & 4821.8 & 1700.2 & 795.5 & 2911.1 & 2086.7 \\
\hline Minimum standard residual (Train) & -4.6 & -4.2 & -5.2 & -6.2 & -3.5 \\
\hline Maximum standard residual (Train) & 4.4 & 8.5 & 6.0 & 5.1 & 7.2 \\
\hline Minimum standard residual (Test) & -1.9 & -3.3 & -1.9 & -2.5 & -1.4 \\
\hline Maximum standard residual (Test) & 4.9 & 4.0 & 5.3 & 4.6 & 5.5 \\
\hline Minimum standard residual (Validation) & -3.1 & -3.4 & -4.9 & -5.2 & -3.6 \\
\hline Maximum standard residual (Validation) & 1.1 & 1.6 & 0.3 & 1.4 & 1.9 \\
\hline
\end{tabular}

Source: Authors.

The basic statistics for R\&D investment predictions from Table 3 and their relation to VA are graphically presented in Figure 3. With the help of the Statistica software, the five most successful neural networks (RBFs) were identified that best described the logic of the regression function. The identified neural networks point in the graph where each of the EU28 countries is located with regards to the optimal amount of investment in R\&D for the period 2013-2017.

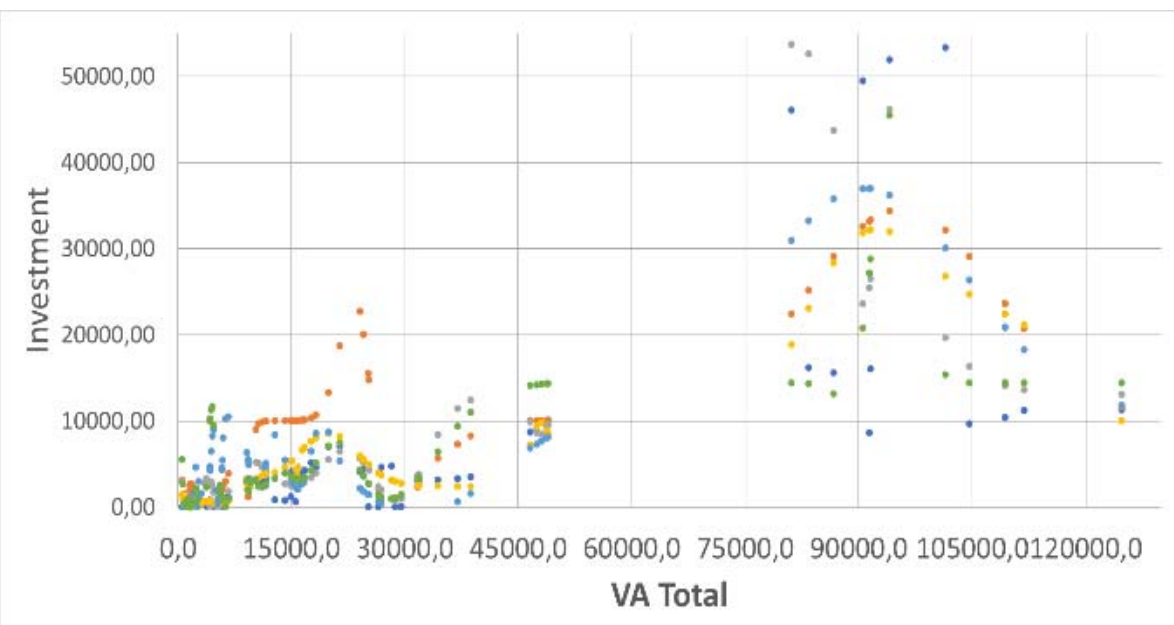

- Investment - 1. RBF 1-16-1 - 2. RBF 1-18-1 - 3. RBF 1-18-1 - 4. RBF 1-21-1 • 5. RBF 1-20-1

Figure 3. Relation between VA and R\&D investment

Source: Authors.

A comparison of the prediction statistics and the real data from the five neural networks showed that neural network No. 1 (RBF 1-16-1) was the most successful, which is graphically presented in Figure 4. The searched values on the (x, y) axis are closest to the point $(0, \max )$, i.e. where the least waste occurs in the ratio between investment and value added. 


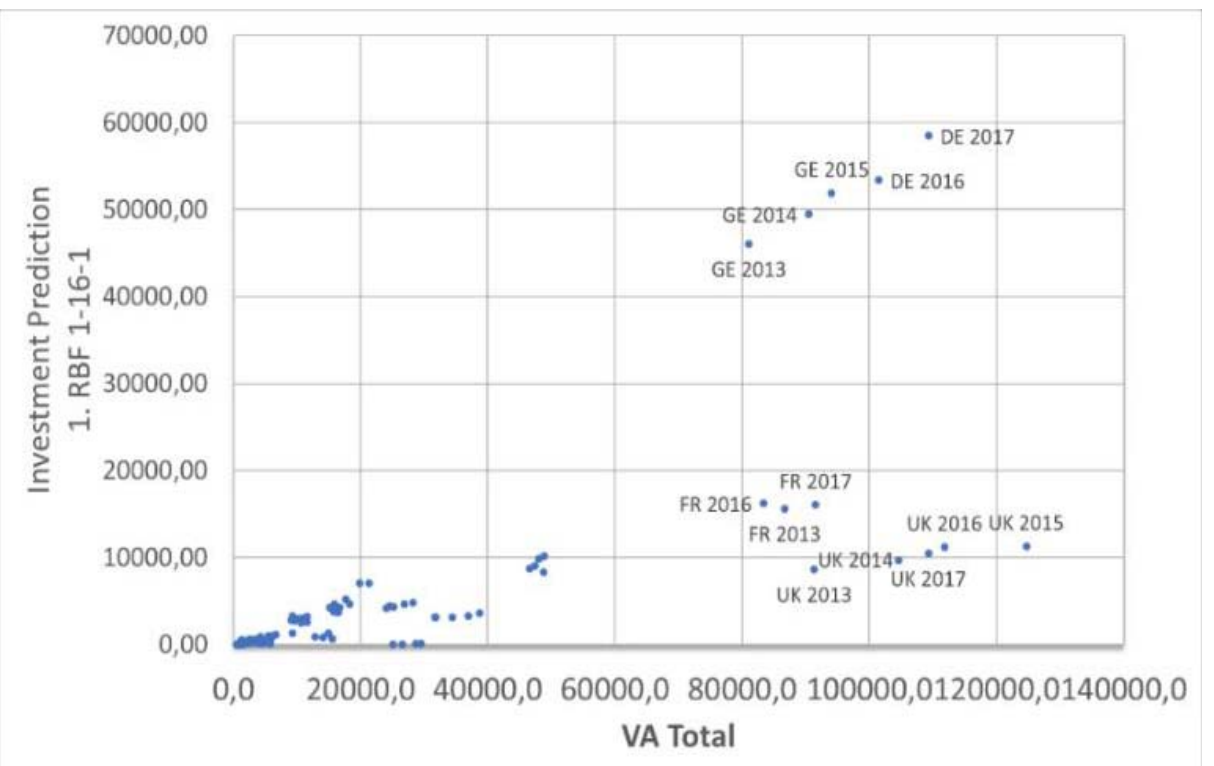

Figure 4. The most successful neural network No. 1 (RBF 1-16-1)

Source: Authors.

In this case, when analysing neural network No. 1 (RBF 1-16-1), it is clear from Figure 4 that for the construction sector, the most optimal ratio of R\&D investment and value added was achieved by the United Kingdom during the monitored period (2013 - 2017). The most successful year for the United Kingdom as a member of the EU28 was 2015. This year, the value of investment in R\&D reached EUR 11.3 billion.

France was another country that, according to neural network No. 1 approached the ideal point (0, max) on the graph. In 2013, investment in R\&D in France amounted to EUR 15.6 billion, and in 2017, EUR 16.1 billion, an increase of EUR 500 million. Despite achieving approximately similar levels of value added, Germany invested more than the United Kingdom during the period under review, but did not reach similar optimum values.

Manufacturing sector. The five most successful neural networks that best describe the logic of the regression function are presented in Table 4.

Table 4. The five most successful neural networks for the manufacturing sector

\begin{tabular}{|c|c|c|c|c|c|c|c|c|c|c|c|}
\hline 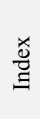 & 咅邑 & 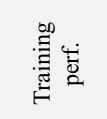 & 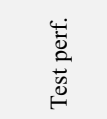 & 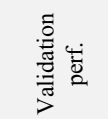 & 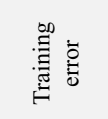 & 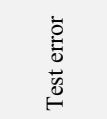 & 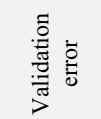 & 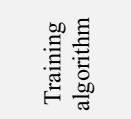 & 壱 危 & 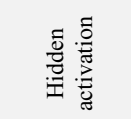 & 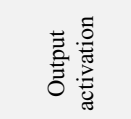 \\
\hline 1 & MLP 1-5-1 & 985507 & 995239 & 0.997513 & 1428085 & 725669.2 & 1246492 & BFGS 66 & SOS & Tanh & Logistic \\
\hline 2 & MLP 1-3-1 & 0.984483 & 0.994447 & 0.996925 & 1525709 & 769331.4 & 1505471 & BFGS 748 & SOS & Tanh & Logistic \\
\hline 3 & MLP 1-3-1 & 0.984451 & 0.994435 & 0.996969 & 1528674 & 770448.9 & 1493403 & BFGS 9999 & SOS & Logistic & $\begin{array}{l}\text { Logistic } \\
\end{array}$ \\
\hline 4 & MLP 1-6-1 & 0.985452 & 0.995294 & 0.997145 & 1434234 & 637001.4 & 870003 & BFGS 140 & SOS & Exponential & Exponential \\
\hline 5 & MLP 1-8-1 & 0.987951 & 0.996519 & 0.997107 & 1226937 & 572504.8 & 561127 & $\begin{array}{l}\text { BFGS } 51 \\
\end{array}$ & SOS & Logistic & Exponential \\
\hline
\end{tabular}

Source: Authors.

Multi-layer perceptron (MLP) networks consist of at least three layers of nodes: input layer, hidden layer, and output layer. The time series are divided into three sets - training, testing and validation. In the hidden and output layers, the following activation functions were considered: Logistic, Exponential and Tanh. A total of 10,000 neural networks were generated, out of which 5 with the best characteristics were retained and used for the calculation of the basic prediction statistics (see Table 5 below). 
Table 5. Basic prediction statistics for investment (manufacturing sector)

\begin{tabular}{|c|c|c|c|c|c|}
\hline \multirow{2}{*}{ Statistics } & \multicolumn{5}{|c|}{ Predictions statistics. Target: Investment } \\
\hline & 1.MLP $1-5-1$ & 2.MLP $1-3-1$ & 3.MLP 1-3-1 & 4.MLP 1-6-1 & 5.MLP 1-8-1 \\
\hline Minimum prediction (Train) & 4.54 & 4.54 & 4.54 & 4.54 & 15.17 \\
\hline Maximum prediction (Train) & 58493.29 & 58493.50 & 58493.50 & 59111.59 & 55018.81 \\
\hline Minimum prediction (Test) & 4.54 & 4.54 & 4.54 & 4.54 & 20.60 \\
\hline Maximum prediction (Test) & 47916.50 & 49546.50 & 49590.97 & 49677.17 & 51255.03 \\
\hline Minimum prediction (Validation) & 4.54 & 4.54 & 4.54 & 4.55 & 42.35 \\
\hline Maximum prediction (Validation) & 58492.41 & 58493.50 & 58493.50 & 56296.32 & 54627.74 \\
\hline Minimum residual (Train) & -4004.35 & -4090.89 & -4055.54 & -3784.10 & -2736.97 \\
\hline Maximum residual (Train) & 5498.27 & 6048.29 & 6064.35 & 6163.58 & 5081.69 \\
\hline Minimum residual (Test) & -3366.29 & -3614.50 & -3626.81 & -3478.81 & -2616.57 \\
\hline Maximum residual (Test) & 1921.24 & 2106.25 & 2090.51 & 1948.49 & 1986.08 \\
\hline Minimum residual (Validation) & -5133.31 & -5134.40 & -5134.40 & -2937.22 & -2855.58 \\
\hline Maximum residual (Validation) & 1600.28 & 1694.08 & 1678.75 & 1212.40 & 825.34 \\
\hline Minimum standard residual (Train) & -3.35 & -3.31 & -3.28 & -3.16 & -2.47 \\
\hline Maximum standard residual (Train) & 4.60 & 4.90 & 4.90 & 5.15 & 4.59 \\
\hline Minimum standard residual (Test) & -3.95 & -4.12 & -4.13 & -4.36 & -3.46 \\
\hline Maximum standard residual (Test) & 2.26 & 2.40 & 2.38 & 2.44 & 2.62 \\
\hline Minimum standard residual (Validation) & -4.60 & -4.18 & -4.20 & -3.15 & -3.81 \\
\hline Maximum standard residual (Validation) & 1.43 & 1.38 & 1.37 & 1.30 & 1.10 \\
\hline
\end{tabular}

Source: Authors.

The relationship between the basic prediction statistics for investment in R\&D (see Table 5) and value added are graphically presented in Figure 50. With the help of the Statistica software programme, the five most successful neural networks were identified (all of them MLP networks). In the graph below, each of the neural networks shows a point where the EU28 countries are situated with regards to the predicted optimal amount of investment in R\&D.

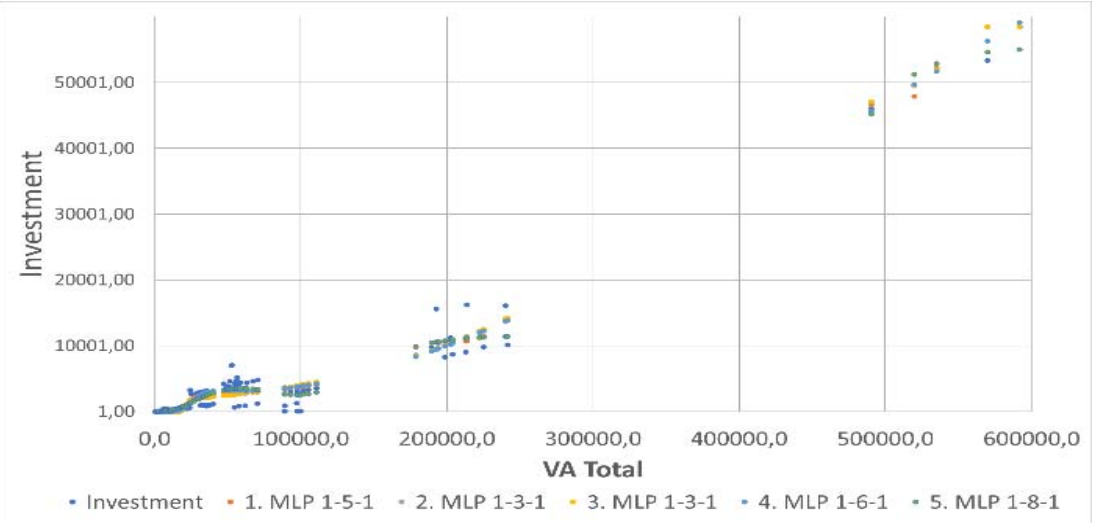

Figure 5. Relationship between VA and investment in R\&D

Source: Authors.

A comparison of the prediction statistics and the real data obtained from the five neural networks showed that neural network No. 5 (MLP 1-8-1) was the most successful (see Figure 6).

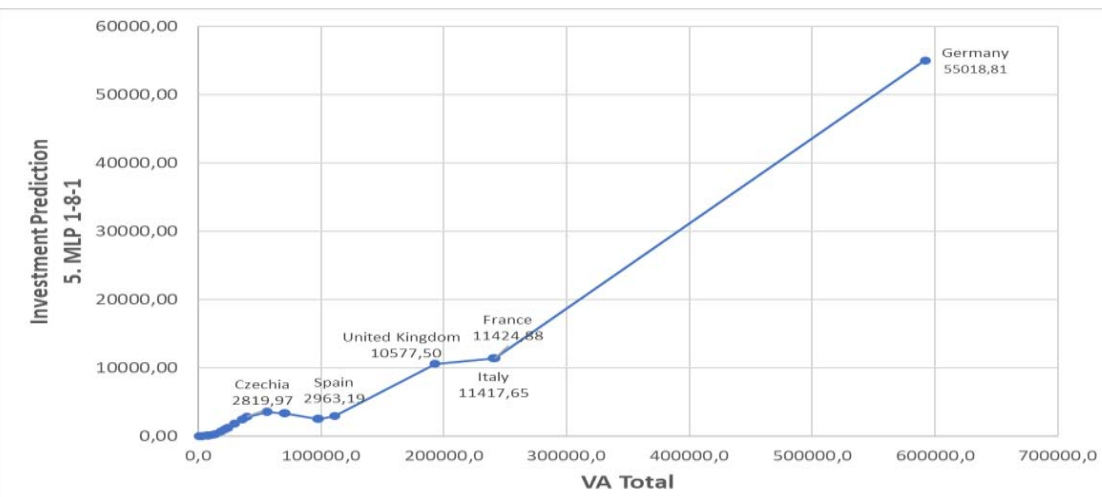

Figure 6. The most successful neural network No. (MLP 1-8-1)

Source: Authors. 
As the VA for the monitored period 2013 - 2017 had similar values, for the clarity of the graphical representation of neural network No. 5 (MLP 1-8-1), the year 2017 was selected to make an evaluation of the EU28 countries.

As can be seen in Figure 6, in the manufacturing sector, the optimal ratio between value added and investment in R\&D was achieved by France ( EUR 11.42 billion), Italy ( $\sim$ EUR 11.41 billion) and Great Britain ( EUR 10.6 billion).

Like in the construction sector, Germany is a country with high investment in R\&D in the manufacturing sector. The funds invested are subsequently reflected in the amount of value added. Germany is undoubtedly a leader in the creation of VA in various industries. However, in terms of the 1:1 ratio (investments: value added), it does not achieve the same optimal results in the manufacturing industry as, for example, France, Italy and Great Britain, where the least waste occurs. In the graph, the Czech Republic achieves a value of EUR 2.8 billion, which, in terms of the 1:1 ratio regarding the optimality of the funds invested, is a positive result.

In the research part, the authors examined the ideal ratio between value added and investment in R\&D in the EU28 countries in the manufacturing and construction sectors. Regression analysis of neural networks was used to analyse the most successful neural networks in these sectors. Scatter plots were used to find the point (0, max) at which the least amount of investment in R\&D was wasted.

In the construction sector, the optimal values were achieved by Great Britain in the year 2015 (EUR 11.3 billion). For many years, Great Britain was one of the EU leaders in creating value added. It is clear that with Brexit at the beginning of 2020, the European Union lost its leader in the creation of value added in the European market. This was reflected in the global market where there is strong competition between Asian and European countries in terms of creating value added. Germany, as another EU leader in creating value added in the construction sector, shows a high level of creating VA during the monitored period, which can be explained by the high standard of living in the country, which is constantly developing itself, as a result of which the construction industry is prospering. Despite the high VA, which is the objective of all national economies, Germany invests high amounts of money in the given sector, but no longer reaches the optimal ratio between the examined variables, unlike, for example, Great Britain and France. The high investment in the given sector in this developed country can be explained by high wage costs and other factors, which are the highest in the EU.

In the manufacturing sector, the optimal ratio between VA and investment in R\&D was achieved by France, Italy and Great Britain. In this sector, Germany did not achieve the optimum between the examined variables, despite the fact that it achieved the highest values. The ideal ratio between investment in R\&D and the resulting VA are therefore the values of this ratio in which investments are not wasted.

\section{Conclusion}

The objective of this contribution was to find to what extent investment in research and development participates in the creation of value added for the EU28 countries. This objective was achieved by means of regression analysis. Neural networks were used to determine the optimal ratio of investment in R\&D to value added. The ratio was shown in a scatter plot, which also showed that the sought optimum of invested funds in R\&D is achieved if the amount of value added is higher than the investment in R\&D.

The results of the research showed that optimal values in the construction sector were achieved by Great Britain during the monitored period (2013-2017); the most successful year for Great Britain as a member of EU28 was 2015 . In this year, the value of investment in R\&D reached $\sim$ EUR 11.3 billion. France, with investment of $\sim$ EUR 16.1 billion in 2017 , came in second place. Despite achieving approximately the same amount of value added and investing more than Great Britain during the monitored period, Germany did not achieve similar optimal values.

In the manufacturing sector, the optimal ratio between VA and investment in R\&D was achieved by France ( EUR 11.42 billion), Italy ( EUR 11.41 billion) and Great Britain ( EUR 10.6 billion). As in the case of the construction sector, Germany is a country that invests highly in R\&D also in the manufacturing sector.

Limitations of the research. In this case, missing data on some countries in Eurostat was a limitation. The authors believe that the data published by the EU countries are correct and calculated using the same methodology.

Practical application. Although the EU countries use the same currency, the standards of living and the historical evolution of the sectors they specialize in makes it difficult to create and compare a dataset for the EU28 countries. However, such comparisons are very useful for the national economies to be able to judge their competitiveness in the European and global market.

Possible direction of further research. Further research could compare the influence of investment on value added using regression analysis, but with a time lag. This would, according to the authors, better describe the relationship between investment and value added.

When comparing the statistical data for the period 2013-2017 on the basis of the predictions made by the identified neural networks using the Statistica software programme as artificial intelligence, it was observed how the given 
programme was trying to predict the future development of investment in R\&D. Its predictive abilities were able to provide a rough estimate that was quite close to the actual value; however, 2 years later. Using the assumption of the possible development, it was able to predict the development of investment in R\&D. When dealing with the issue of investment, it is necessary to take into account the time lag with regards to returns, which is more than one year in most cases. The application of neural networks can therefore be considered a suitable method for predicting possible developments. Of course, no artificial intelligence is able to predict the development with complete accuracy if it does not include uncontrollable factors, such as economic crises, ecological disasters, or pandemics in its calculations. However, its predictive abilities can be useful for the purposes of strategic planning of companies in a given sector.

\section{References}

1. European Commission, European Innovation Scoreboard 2020. Luxembourg: Publications Office of the European Union (2020)

2. European Statistical Office (Eurostat), Smarter, greener, more inclusive? Indicators to support the Europe 2020 strategy. Luxembourg: Publications Office of the European Union (2020)

3. Technology Centre of the CAS, Potenciál růstu soukromých investic ve výzkumu, vývoji a inovacích mající vliv na strukturu ekonomiky, zaměstnanost a veřejné rozpočty [Growth potential of private investments in research, development and innovation affecting the structure of the economy, employment and public budget]. [online]. Available at: https://www.spcr.cz/aktivity/z-hospodarske-politiky/12541-cesko-potrebuje-zlepsit-podminky-provyzkum-vyvoj-a-inovace (2018)

4. T. Ylömäki, Global Value Chain Upgrading. The Research Institute of the Finnish Economy (ETLA), ETLA Working Papers. 36 (2016)

5. C. Pietrobelli, R. Rabellotti, Global value chains meet innovation systems: Are there learning opportunities for developing countries? World Development. 39, 1261-1269 (2011)

6. J. Hirshleifer, Investments Decision under Uncertainty: Choice - Theoretic Approaches. The Quarterly Journal of Economics. 79, 509-36 (1965)

7. S. Lee, D. Olson, Convergenomics: Convergenomics: Strategic Innovation in the Convergence Era. Surrey: Gower Publishing (2010)

8. M. T. Hansen, J. Birkinshaw, The Innovation Value Chain. 85, Harvard Business Review. 121-130 (2007)

9. S. Roper, S. Arvabitis, From knowledge to value added: A comparative, panel-data analysis of the innovation value chain in Irish and Swiss manufacturing firms. Research Policy. 41(6), 1093-1106 (2012)

10. S.M. Lee, S. Trimi, Innovation for creating a smart future. Journal of Innovation \& Knowledge. 3(1), 1-8 (2018)

11. M. Halaskova, B. Gavurova, S. Korony, Change of EU28 countries research and development indicators between 2010 and 2015. Economics and Sociology. 13(1), 230-248 (2020)

12. A. Rodríguez-Pose, R. Crescenzi, Research and development, spillovers, innovation systems, and the genesis of regional growth in Europe. Regional studies. 42(1), 51-67 (2008)

13. S. Kergroach, National innovation policies for technology upgrading through GVCs: A cross-country comparison. Technological Forecasting and Social Change. 145, 258-272 (2019)

14. L. Tajoli, G. Felice, Global Value Chains Participation and Knowledge Spillovers in Developed and Developing Countries: An Empirical Investigation. The European Journal of Development Research. 30, 505-532 (2018)

15. R. Lema, R. Rabellotti, P. Gehl Sampath, Innovation Trajectories in Developing Countries: Co-evolution of Global Value Chains and Innovation Systems. The European Journal of Development Research. 30, 345-363 (2018)

16. C. Jona-Lasinio, S. Manzocchi, V. Meliciani, Knowledge based capital and value creation in global supply chains. Technological Forecasting and Social Change. 148 (2019)

17. K. Reddy, R. Chundakkadan, S. Sasidharan, Firm innovation and global value chain participation. Small Business Economics. (2020)

18. X. González, C. Pazó, Do public subsidies stimulate private R\&D spending? Research Policy. 37, 371-389 (2008)

19. Z. Potuzakova, J. Ohm, R\&D Investments, EPO Patent Applications and the Economic Heterogeneity within the EU. Review of Economic Perspectives. 18(2), 177-191 (2018)

20. Archive of European integration, Barcelona European Council 15-16 March 2002. Presidency conclusions. [online]. Available at: http://aei.pitt.edu/43345/ (2002) 
21. N. Albu, Research and Development Spending in the EU: 2020. Growth Strategy in Perspective. SWP Working Paper. 1(8) (2011)

22. Eurostat. Gross domestic expenditure on $R \& D$ [online]. Available from: https://ec.europa.eu/eurostat/tgm/table.do?tab=table\&init=1\&language=en\&pcode=t2020_20\&plugin=1 (2020)

23. Office of the Government of the Czech Republic, Innovation Strategy of the Czech Republic 2019-2030 [online]. Available at: https://www.vyzkum.cz/FrontAktualita.aspx?aktualita=867990 (2019)

24. A. Ruser, H. K. Anheier, The EU's Future Role on the Global Stage. Global Policy. 5(1) (2014)

25. J. W. Lee, Lagged Effects of R\&D Investments on Corporate Market Value: Evidence from Manufacturing Firms Listed in Chinese Stock Markets. The Journal of Asian Finance, Economics and Business. 7(8), 69-76 (2020)

26. C. T. Albulescu, D. Goyeau, EU Funds Absorption Rate and the Economic Growth. Timisoara Journal of Economics and Business. 6(20), 153-170 (2013)

27. P. K. Ozili, T. Arun, Spillover of COVID-19: Impact on the Global Economy. SSRN Electronic Journal. (2020)

28. I. S. Didych, O. Pastukh, Y. Pyndus, O. Yasniy, The evaluation of durability of structural elements using neural networks. Acta Metallurgica Slovaca. 24(1), 82-87 (2018)

29. M. Vochozka, J. Horak, T. Krulicky, Innovations in Management Forecast: Time Development of Stock Prices with Neural Networks. Marketing and Management of Innovations. 2020(2), 324-339 (2020) 